\title{
Physical-Mechanical Properties of Cement Stabilized RAP/Crushed Stone Aggregate Mixtures
}

\author{
Ksenija ĐOKOVIĆ, Simo TOŠOVIĆ, Ksenija JANKOVIĆ, Nenad ŠUŠIĆ
}

\begin{abstract}
The paper presents and analyzes the results of testing the properties of cement stabilized mixtures of reclaimed asphalt pavement (RAP) and crushed stone aggregate (CSA). Tests were carried out on reclaimed asphalt pavement and crushed stone aggregate mixtures with varying RAP content $(0 \%, 20 \%, 40 \%, 60 \%$ and $80 \%)$, as well as with a varying addition of cement $(3 \%, 5 \%$ and $7 \%)$. The purpose of these tests was to determine the optimal proportion of recycled asphalt pavement in a mixture with crushed stone aggregate, and the optimal addition of cement as a hydraulic binder. Furthermore, the aim was to determine physical-mechanical parameters: the indirect tensile strength $\left(R_{t}\right)$ and the dynamic modulus of elasticity $(E)$, which are applied in pavement design during the process of cold recycling. On the basis of the obtained values, categorization of the stabilized mixture was carried out according to the standard EN 14227-10: 2006, which continues to be applied in the design of pavements. The maximum proportion of recycled asphalt in the stabilized mixture was determined as being up to $60 \%$; the stabilized mixture was categorized into the "T1" and "T2" categories - gravelly soils.
\end{abstract}

Keywords: cement stabilized mixtures; cold recycling; dynamic modulus of elasticity; indirect tensile strength; reclaimed asphalt pavement

\section{INTRODUCTION}

In the 1980s, first in the United States, and later in Europe, technology began deep recycling using the cold process. Cold recycling technology is suitable for use in the rehabilitation of roads in order to save natural materials, reduce the impact of environmental pollution and increase protection. The cold recycling process involves the removal, shredding and re-use of existing material from the upper layers of the pavement structure [1, 2]. As the physical-mechanical properties of the building material (mixed asphalt mixtures) become worse due to exploitation, in order to improve them, stabilization is necessary. Stabilization is performed by improving the granulometric composition, i.e.with the missing fractions of the aggregates and the hydraulic binder [3, 4]. As a binder, cement, lime, ash or some other modern chemical additives in powder or liquid state, produced by different manufacturers, can be used and are increasingly available in our market. The most important physical-mechanical properties of the mixture thus prepared are the strength of the material (compressive and indirectly tensile) and the modulus of elasticity. Based on the value of tensile strength and dynamic modulus of elasticity, it is possible to classify stabilized mixtures, design a pavement structure, and control the conditions of installation in the performance of cold recycling.

\section{PROPERTIES OF BASIC MATERIAL MIXTURES}

For the purpose of determining the parameters necessary for the design of the pavement structure, as well as the optimal proportion of reclaimed asphalt pavement in the mixture with crushed stone aggregate, appropriate tests were carried out. Stabilization mixtures were made so that the proportion of reclaimed asphalt pavement in the crushed stone aggregate was $0 \%, 20 \%, 40 \%, 60 \%$ and $80 \%$. The tests were carried out with different percentages of cement: $3 \%, 5 \%$ and $7 \%$ in the dry weight of the material [5].

Also, the mixture was sieved and the granulometric composition determined, as was the chemical composition of the hydraulic binder/cement used.

\subsection{Physical-Mechanical Properties of Crushed Stone Aggregates and Reclaimed Asphalt Pavement}

Fig. 1 shows the grain size distribution of crushed stone aggregates and reclaimed asphalt pavement, whilst in Fig. 2, the granulometric curves of stabilized mixtures for different fractions of reclaimed asphalt pavement and crushed aggregate [5] are shown. Crushed stone aggregate has a coefficient of uniformity $C_{\mathrm{u}}=63.24$ and reclaimed asphalt pavement $C_{\mathrm{u}}=9.84$ (Fig. 3).

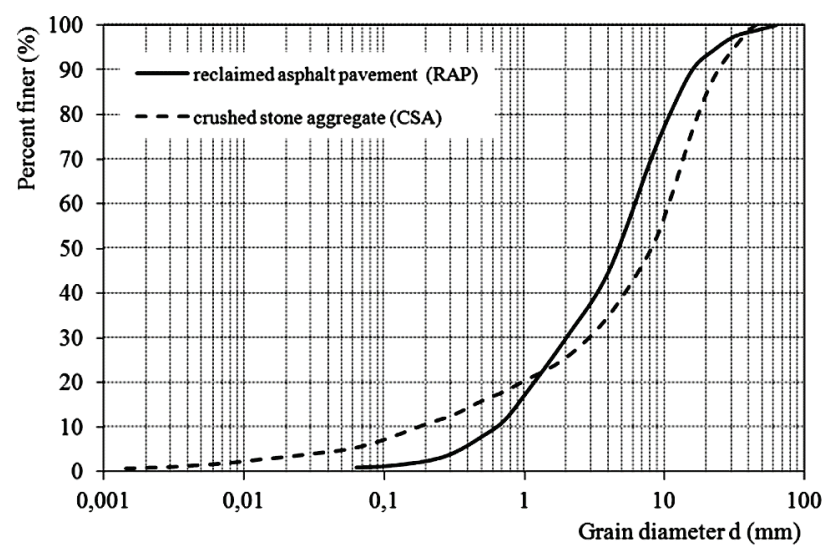

Figure 1 Diagram of particle size distribution

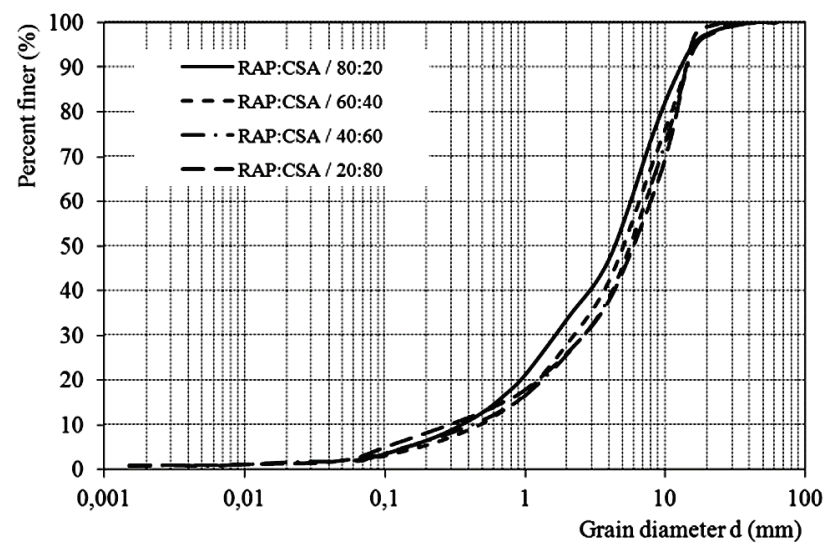

Figure 2 Diagram of particle size distribution for different parts of reclaimed asphalt pavement and crushed stone aggregates 
Increasing the use of reclaimed asphalt pavement in the mixture decreases the coefficient of uniformity $\left(C_{\mathrm{u}}\right)$, which can be explained by the fact that the reclaimed asphalt pavement has a much lower coefficient of uniformity of the material in the upper bearing layer of the crushed stone aggregate. Also, the coefficient of curvature $\left(C_{\mathrm{C}}\right)$ decreases as the percentage of reclaimed asphalt pavement in the mixture increases, from the value of $C_{\mathrm{C}}=$ $4.6 \%$ to $0 \%$ for asphalt and $C_{\mathrm{C}}=1.4 \%$ to $80 \%$ for the asphalt mixture. Based on the changes in the coefficient of curvature, it can be concluded that a greater portion of asphalt in the mixture results in a continuous grading curve (equal distribution of fractions).

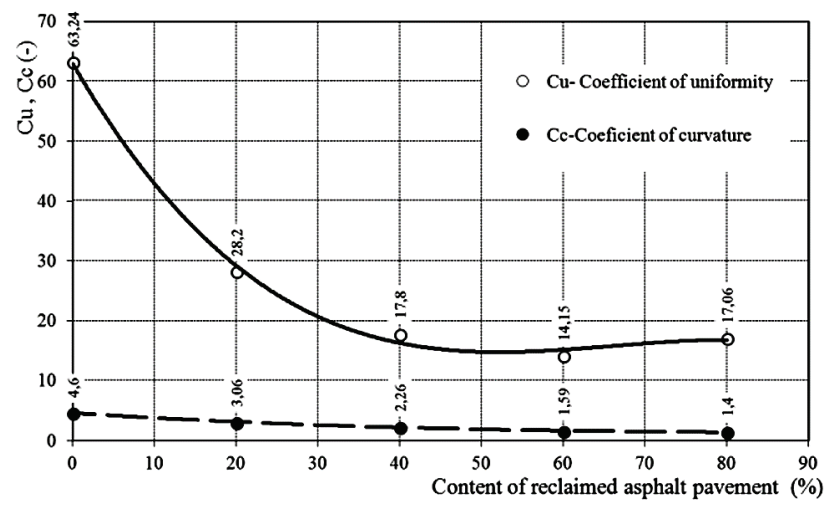

Figure 3 Coefficients $C_{\mathrm{u}}$ and $C_{\mathrm{C}}$ as a function of the percentage of reclaimed asphalt pavement in the mixture

\subsection{Composition and Chemical Properties of Cement}

As the stabilized layer should have adequate strength and elasticity, in studies the hydraulic road binder HRB E4 (cement B) was used as a binder, specially designed for stabilization. Cement B satisfies the criteria required for hydraulic binders for use in roadways according to the standard SRPS EN 13282-1: 2015 (HRB 32.5).

Tab. 1 shows the chemical composition of cement B used in the test.

Table 1 Chemical composition of cement $B$

\begin{tabular}{|c|c|}
\hline Oxide content (\%) & Cement B \\
\hline $\mathrm{SiO}_{2}$ & 27.11 \\
\hline $\mathrm{Al}_{2} \mathrm{O}_{3}$ & 8.05 \\
\hline $\mathrm{Fe}_{2} \mathrm{O}_{3}$ & 3.0 \\
\hline $\mathrm{MnO}$ & 0.095 \\
\hline $\mathrm{MgO}$ & 2.91 \\
\hline $\mathrm{CaO}$ & 50.28 \\
\hline $\mathrm{SO}_{3}$ & 1.98 \\
\hline $\mathrm{S}^{2-}$ & 0.03 \\
\hline $\mathrm{Na}_{2} \mathrm{O}$ & 0.36 \\
\hline $\mathrm{K}_{2} \mathrm{O}$ & 0.56 \\
\hline Loss on ignition & 5.78 \\
\hline
\end{tabular}

\section{PROPERTIES OF CEMENT STABILIZED RAP/CRUSHED STONE AGGREGATE MIXTURES}

The following physical and mechanical properties were tested on the prepared stabilized mixtures: compressive strength, indirect tensile strength, dynamic modulus of elasticity, and resistance to frost.

\subsection{The Unconfined Compressive Strength of the Stabilized Mixture}

Unconfined compressive strength was determined according to the standard SRPS ISO 4012:2000 Determination of compressive strength of test specimens concrete [6].

Fig. 4 shows the values of the unconfined compressive strength obtained after 28 days of sample care in a humid chamber, as a function of the percentage content of cement. The trial samples were prepared with varying percentages of reclaimed asphalt pavement, and with dry density and moisture content, obtained by the Modified Proctor Test. All samples were made with the same type of B cement.

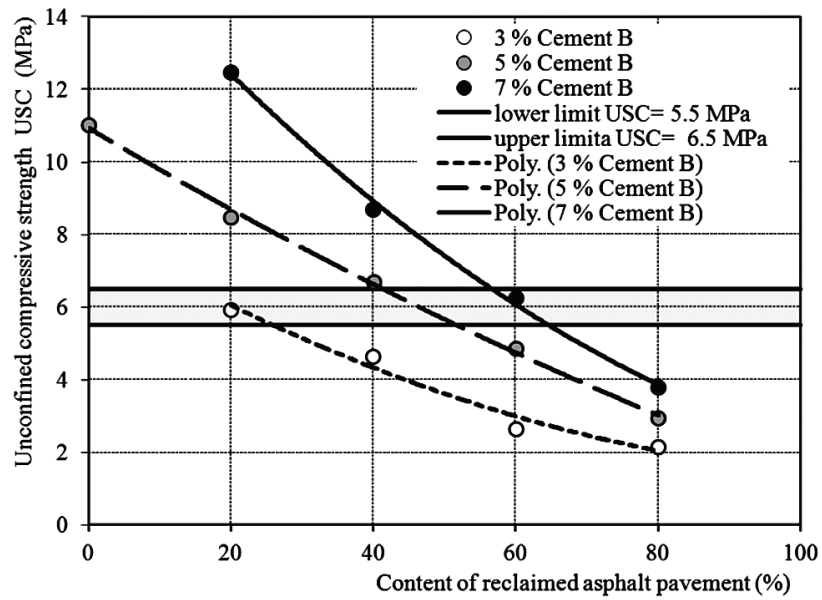

Figure 4 Unconfined compressive strength of stabilized mixtures for different cement content after 28 days

From the diagram in Fig. 4, it is evident that with 3\% cement in the recycling process, it is possible to achieve a minimum strength of USC $=3.0 \mathrm{MPa}$ for a stabilized mixture with about $50 \%$ reclaimed asphalt pavement in the mix, which is actually the lower limit of the minimum compressive strength according to the technical specifications. If recycling is carried out with $3 \%$ cement, the recycled asphalt pavement should make up at least $15 \%$ of the mixture in order to achieve a maximal compressive strength of $U S C=6.5 \mathrm{MPa}$, and $25 \%$ to achieve a minimal strength of $U S C=5.5 \mathrm{MPa}$.

The optimum value of unconfined compressive strength can be achieved with a maximum of $5 \%$ cement, resulting in a compressive strength of approximately USC $=6.5 \mathrm{MPa}$ after 28 days of sample care in a humid chamber, although the content of reclaimed asphalt pavement should not be greater than $50 \%$.

Theoretically, it is possible to stabilize the mixture with $60 \%$ content of recycled asphalt pavement with a cement percentage of at least $7 \%$, in order to meet the compressive strength requirements set out in the technical specifications for the cold recycling process.

The optimal percentage of cement for cold recycling is $5 \%$ added to the dry weight of the mixture, with up to $50 \%$ content of recycled asphalt pavement.

Fig. 5 shows the changes in unconfined compressive strength according to the percentage of cement in the range of $3 \%-7 \%$, for different ratios of reclaimed asphalt pavement and crushed stone aggregate content. From the diagram, the impact of reclaimed asphalt pavement content 
on the compressive strength is clear, i.e. with an increase in the percentage of reclaimed asphalt pavement, the compressive strength decreases. Stabilizer mixtures with $60 \%$ and $80 \%$ reclaimed asphalt pavement are below the lower limits for compressive strength, which is in the range of 5.5 to $6.5 \mathrm{MPa}$.

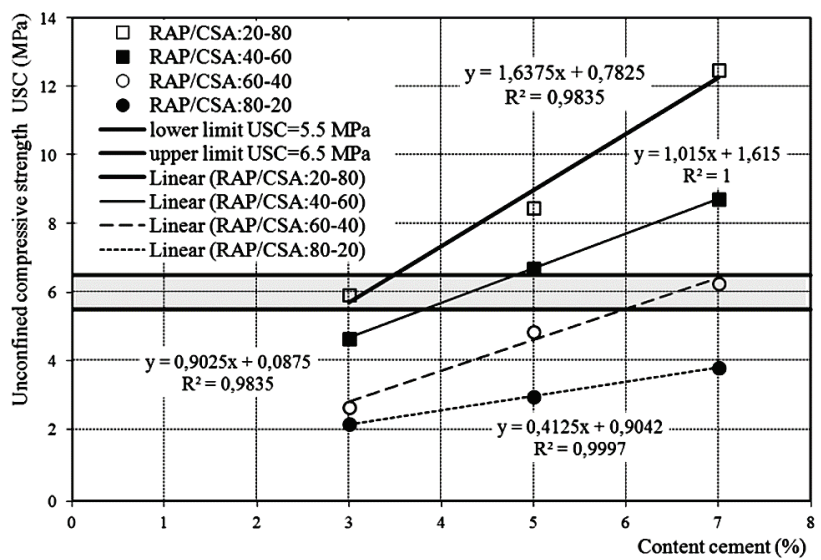

Figure 5 Unconfined compressive strength of stabilized mixtures for different contents of RAP after 28 days

A stabilized mixture with a reclaimed asphalt pavement content of more than $50 \%$ should stabilize the foamed bitumen with a minimum content of cement up to $1.5 \%$ in order to achieve initial strength. A stabilized mixture with a reclaimed asphalt pavement content of under $50 \%$ may be stabilized with the optimal addition of about $5 \%$ cement.

\subsection{Indirect Tensile Strength of the Stabilized Mixture (ITS)}

Indirect tensile strength was determined according to the standard test method for tensile splitting strength of test specimens-SRPS ISO 4108:2000, the so-called Brazilian Test [7].

Fig. 6 shows the values of indirect tensile strength (ITS) obtained by the Brazilian test.

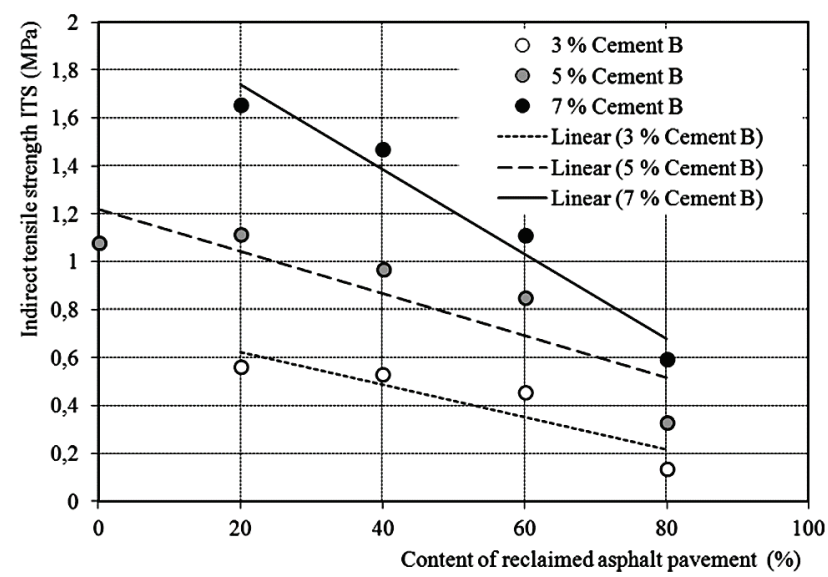

Figure 6 Indirect tensile strength of stabilized mixtures for different cement content after 28 days

Indirect tensile strength values decrease with an increase in the percentage of reclaimed asphalt pavement in the mixture. ITS reaches its highest value in the mixture with $20 \%$ reclaimed asphalt pavement and 7\% cement content $(I T S=1.66 \mathrm{MPa})$.
ITS values $>0.2 \mathrm{MPa}$ were obtained in mixtures in which the proportion of reclaimed asphalt pavement $>60 \%$ with the addition of $3 \%, 5 \%$ and $7 \%$ cement in relation to the dry weight of the mixture.

Upon the recommendations of the study "Technical Guide - Treatment of soil with lime and/or hydraulic binder, Setra, September 2007", for mixtures with ITS > $0.2 \mathrm{MPa}$, the stabilized material is resistant to frost [8].

The indirect tensile strength ranged from $8 \%$ to $17 \%$ compared to the compressive strength determined after 28 days.

In line with the recommendation of the above study [8], the following equation was adopted for calculating the tensile strength $R_{\mathrm{t}}$ :

$$
R_{\mathrm{t}}=0.8 \times I T S
$$

Fig. 7 shows the indirect tensile strength values determined in mixtures with different percentages of reclaimed asphalt pavement. Based on the obtained results, it can be concluded that an ITS of less than $0.2 \mathrm{MPa}$ is exhibited by a mixture of $80 \%$ reclaimed asphalt pavement, and with about $3 \%$ cement, which, according to the results of study [8], does not satisfy the requirements for being resistant to frost action $($ ITS $<0.2)$.

According to study [8], those mixtures in which the indirect tensile strength is greater than $0.4 \mathrm{MPa}$ acquire satisfactory stabilization. This is achieved by the asphalt content being up to $60 \%$ for all percentages of cement used in the stabilization.

The test results for indirect tensile strength allow a greater content of reclaimed asphalt pavement in a mixture of about $10 \%(60 \%)$ than the criterion obtained by compressive strength $(50 \%)$.

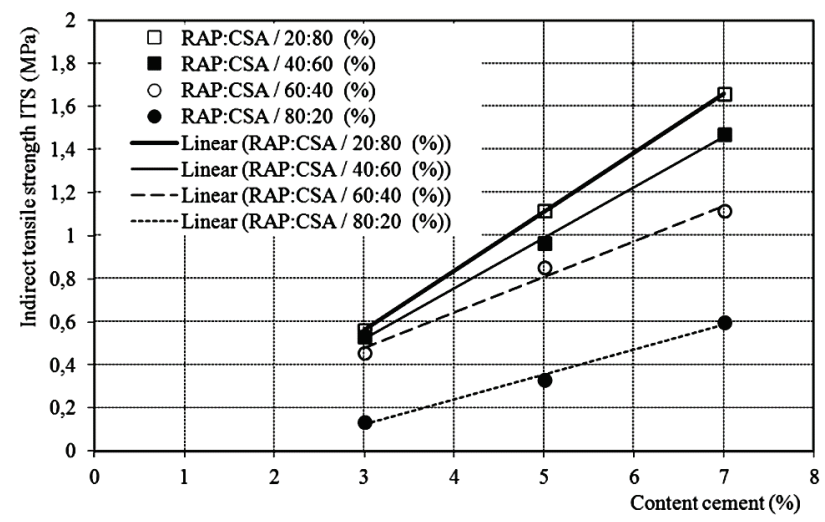

Figure 7 Indirect tensile strength of stabilized mixtures for different reclaimed asphalt pavement content after 28 days

\subsection{Dynamic Modulus of Elasticity - $E$ Modulus}

Due to the nature of the dynamic loading of the pavement structure, it is of particular importance to determine the dynamic modulus of elasticity $(E)$. In addition to being used in designing a pavement structure, a dynamic modulus of elasticity can also be used for the classification of stabilized mixtures. This parameter can be obtained on the basis of the empirical dependence between the modulus of elasticity and the compressive strength at 28 days and the measurement of the ultrasound method. 


\subsubsection{Determining the Dynamic Modulus of Elasticity by the Ultrasound Method}

The principle of determining the dynamic modulus of elasticity using the ultrasonic method is based on determining the passage of time of the longitudinal waves through the base of a sample of a certain length. In contrast to the resonant frequency method, the ultrasound method does not depend on the shape of the sample, but on the elastic properties of the environment, which is why it is often used in field trials. According to recommendations for implementing the ultrasonic test method, the required frequency range for samples up to $50 \mathrm{~mm}$ is from 60 to 200 $\mathrm{kHz}$.

The ultrasonic testing equipment consisted of a pulse generator, transmitter, receiver, electric impulse amplifier and timer. The appearance of the ultrasound equipment and the disposition of performing the test are shown in Fig. 8.

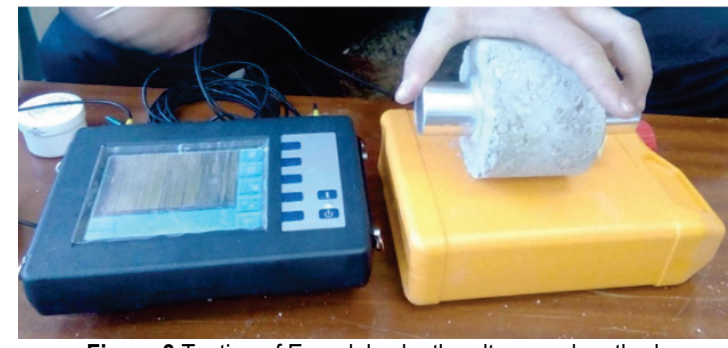

Figure 8 Testing of E modulus by the ultrasound method

The passage time of the longitudinal waves was measured from the moment the impulse was sent to the base of the sample until it was received at the opposite base, and is denoted by $T$. The ultrasound velocity $(V)$ was determined according to Eq. (2) [9]:

$V=\frac{L}{T}$

where: $L$ is the sample length, in $\mathrm{m} ; T$ is the time of the ultrasound wave propagation through the sample, in $\mathrm{s}$.

After measuring the ultrasound velocity, the modulus of elasticity $(E)$ was calculated according to Eq. (3):

$E=\frac{\rho V^{2}[(1+v)(1-2 v)]}{(1-v)}$

where: $V$ is the velocity of the longitudinal waves obtained by measuring the ultrasound method; $\rho$ is density $\left(\mathrm{kg} / \mathrm{m}^{3}\right)$; $v$ is the Poisson ratio.

According to the literature on data for cement stabilized materials, the values of the Poisson ratio range between 0.15 and 0.30 . The value of 0.25 was adopted for the calculation implemented [3].

Figs. 9 and 10 show the signals of the ultrasound testing. A comparison of the figures clearly reveals a difference between the appearance of the signal for pure crushed stone aggregate (Fig. 9) and that for a mixture of crushed stone aggregate and reclaimed asphalt pavement (Fig. 10), both with the addition of $3 \%$ cement.

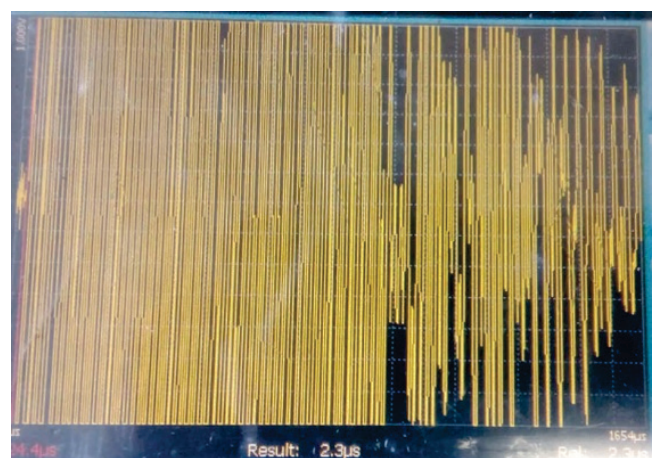

Figure 9 The signal of the crushed aggregate $0 / 31.5 \mathrm{~mm}$

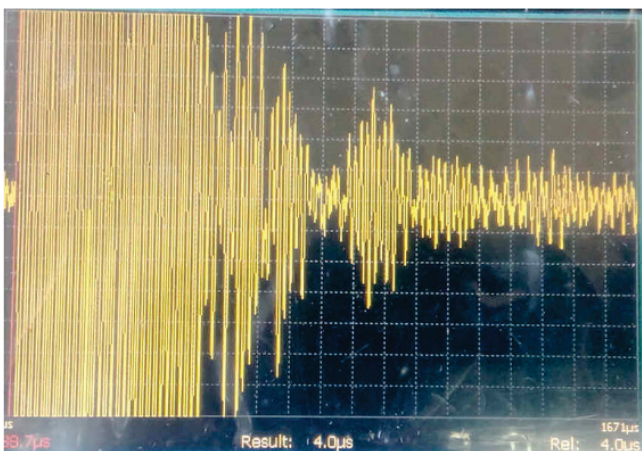

Figure 10 The signal of material stabilized with crushed stone aggregate 0/31.5 $\mathrm{mm}(60 \%)$ and reclaimed asphalt pavement $(40 \%)$ with $3 \%$ added cement

Fig. 11 shows a diagram of the dynamic modulus of elasticity $(E)$ and the different content of reclaimed asphalt pavement for different percentages of cement. The dynamic modulus of elasticity was obtained by the ultrasound method.

From Fig. 11 it can be clearly observed that, when cement content is the same, elasticity moduli exhibit a decreasing trend as the percentage of reclaimed asphalt pavement in the mixture increases. The coefficient of determination is extremely high, ranging from 0.82 to 0.96 .

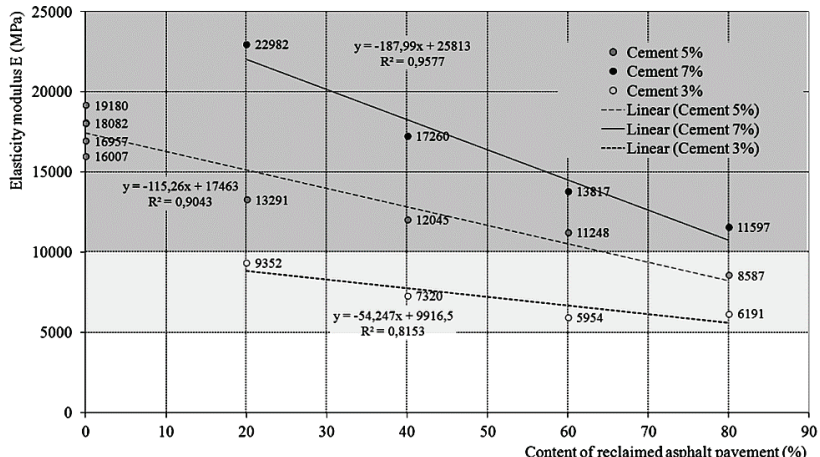

Figure 11 Diagram of the dynamic moduli of elasticity $E$ and the content of cement [5]

The values obtained for $E$ moduli can be divided into two groups:

- $\quad E$ moduli of 5000 to $10000 \mathrm{MPa}$, which were moduli obtained when stabilizing with $3 \%$ cement and a reclaimed asphalt pavement content of $20 \%$ to $80 \%$.

- $E$ moduli of 10000 to $23000 \mathrm{MPa}$, which were obtained when stabilizing the mixture with $5 \%$ and $7 \%$ cement and a reclaimed asphalt pavement content of $20 \%$ to $80 \%$.

$E$ moduli increased for different percentages of added cement when the reclaimed asphalt pavement content in the 
mixture was the same. The mixture with $20 \%$ reclaimed asphalt pavement increased by $7000 \mathrm{MPa}$, the mixture with $40 \%$ increased by $5000 \mathrm{MPa}$, while the mixture with $80 \%$ increased by about $2000 \mathrm{MPa}$.

\subsubsection{Determination of the Dynamic Modulus of Elasticity from the Compressive Strength}

The equation for determining the $E$ modulus for stabilizing coarse grained materials with cement is given by the following formula $[3,10]$ :

$E_{\mathrm{v}}=57500 P_{\mathrm{c}}^{1 / 2}(\mathrm{psi})$

where: 1 psi $=6894.76 \mathrm{~Pa} ; E_{\mathrm{v}}$ - Modulus of elasticity $(\mathrm{MPa}) ; P_{\mathrm{c}}$ - Compressive strength $(\mathrm{MPa})$.

Table 2 Expected values of the modulus of elasticity depending on the compressive strength [3]

\begin{tabular}{|c|c|c|}
\hline Type of material & $E(\mathrm{MPa})$ & Author \\
\hline \multirow{2}{*}{ Lean concrete } & 15000 & Verstraeten \\
\hline & $15000-38000$ & Golden \\
\hline \multirow{2}{*}{ Cement stabilized sand } & 15000 & Bolk \\
\hline & 12000 & Autret \\
\hline Cement stabilized gravel & 20000 & Autret \\
\hline Cement stabilized gravel & $15000-20000$ & Babić \\
\hline
\end{tabular}

Tab. 2 [3] shows the expected values of the moduli of elasticity depending on the value of the compressive strength for cement stabilized materials by different authors.

\section{CLASSIFICATION OF CEMENT STABILIZED RAPICRUSHED AGGREGATE MIXTURES}

The obtained values of tensile strength $\left(R_{\mathrm{t}}\right)$ and dynamic elasticity modulus $(E)$ were used for the classification of the stabilized mixtures, according to the diagram $R_{\mathrm{t}}=F(E)$ in Fig. 12, taken from the above study and standards [8, 11 and 12].

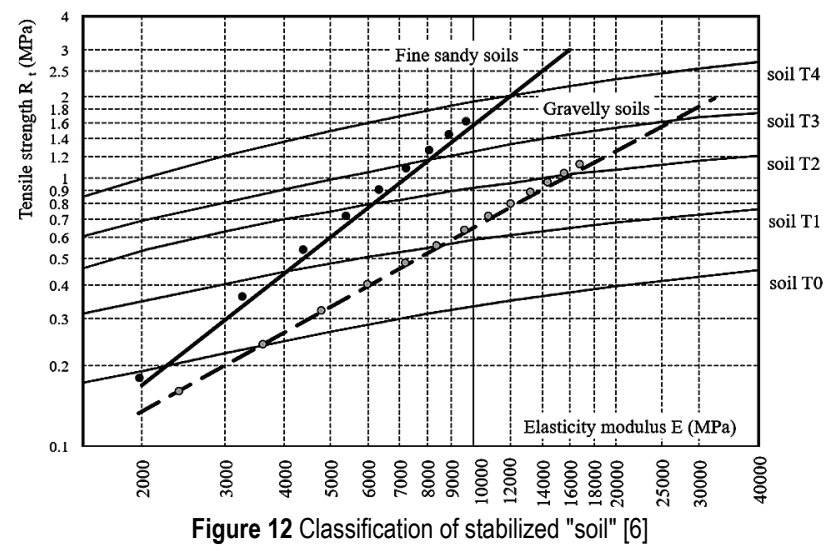

From the diagram in Fig. 12, it is apparent that materials classified as gravelly soils (GW, GP) have a gentler curve than sandy soils (SW, SP), due to higher $E$ modulus values during stabilization and where tensile strength $R_{\mathrm{t}}$ values are the same.

The stabilized materials were divided into classes of soil from $\mathrm{T} 0$ to $\mathrm{T} 5$ with characteristics that are discussed in detail in study [8].
The values obtained for the indirect strength stability and modulus of elasticity of the tested stabilized mixtures of reclaimed asphalt pavement and crushed stone aggregates are given in a diagram for classification and are shown in Fig. 13

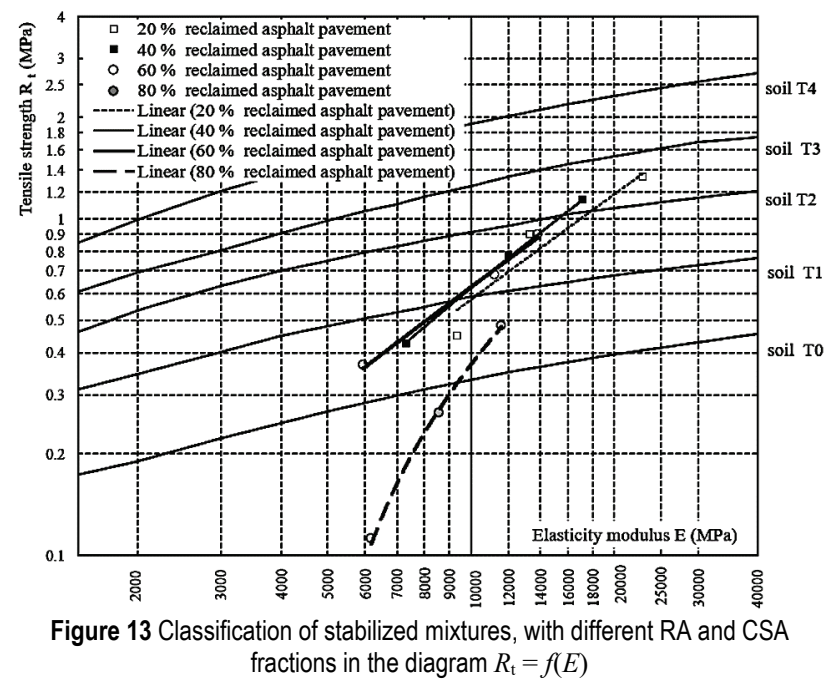

The slope of the line depicting tensile strength as a function of the $E$ moduli, in stabilized mixtures, corresponds approximately to "gravelly" soil. Significant deviation of the slope of the line was exhibited for mixtures with $80 \%$ reclaimed asphalt pavement which are stabilized with the addition of $3 \%, 5 \%$ and $7 \%$ cement.

The mixtures for stabilization with up to $20 \%, 40 \%$ and $60 \%$ reclaimed asphalt pavement content and with $3 \%$ cement are classified as stabilized soil "Soil T1", with 5\% cement as class "Soil T2", and with 7\% cement as class "Soil T3".

The mixtures for stabilization with up to $60 \%$ reclaimed asphalt pavement content, which is the lower limit of the maximum asphalt content, have characteristics similar to stabilized soil, i.e. gravel with a binder.

\section{CONCLUSION}

Based on the physical and mechanical characteristics of the stabilized material with a hydraulic binder (indirect tensile strength and dynamic modulus of elasticity), the maximum content of reclaimed asphalt pavement in the stabilized mixture has been determined to be up to $60 \%$. According to the criterion of unconfined compressive strength, it is recommended that the percentage of reclaimed asphalt pavement be at a maximum of $50 \%$.

Based on the tests, the pairs $R_{\mathrm{t}}-E$ (tensile strength $R_{\mathrm{t}}$ and dynamic elasticity modulus $E$ ) were determined, as required for design, and their values are shown for stabilized mixtures with different reclaimed asphalt pavement and hydraulic binder percentages in the mixtures.

An evaluation of the stabilized mixtures with different percentages of reclaimed asphalt pavement and hydraulic bonding agent was performed, according to the "soil" classes"T0" to "T5".

The obtained values of $R_{\mathrm{t}}$ and $E$, and the categorization of stabilized mixtures into "T0-T4" have further application in the design of pavement structures. 


\section{Acknowledgments}

The results presented in this paper have been obtained as part of research conducted within the scope of the project TR 36014 - Geotechnical Aspects of the Research and Development of Modern Technologies for the Construction and Rehabilitation of Municipal Solid Waste Landfills, funded by the Ministry of Education, Science and Technological Development of the Republic of Serbia.

\section{REFERENCES}

[1] Cvetanović, A. \& Banić, B. (2004). Kolovozne konstrukcije. Beograd, Akademska misao.

[2] Androjić, I. \& Kaluđer, G. (2013). Cold recycling of asphalt pavements using foamed bitumen and cement. Građevinar, 65(5), 463-471.

[3] Barišić, I., Rukavina, T., \& Dimter, S. (2011). Cementne stabilizacije - karakteriziranje materijala i projektni kriteriji. Građevinar, 63(2), 135-142.

[4] Rukavina, T., Dragićević, V., Lopuh, S., \& Rajić, S. (2007). Methods used for soil stabilization during construction of transportation facilities. Građevinar, 59(4), 301-309.

[5] Study of the physical-mechanical properties of stabilized mixtures of crushed stone aggregates $0-31.5 \mathrm{~mm}$ and reclaimed asphalt pavement with cement addition, Institute IMS, 2017 (in Serbian).

[6] SRPS ISO 4012:2000 - Determination of compressive strength of test specimens - concrete.

[7] SRPS ISO 4108:2000 - Determination of tensile splitting strength of test specimens - concrete.

[8] Technical Guide - Treatment of soil with lime and /or hydraulic binders; Part 2.3 Design parameters, 2.3.1.

[9] EN 12504-4:2004: Testing concrete - Part 4: Determination of ultrasonic pulse velocity.

[10] Arellano, D. \& Thompson, M. R. (1998). Final Report: Stabilized Base Properties (Strength, Modulus, Fatigue) for Mechanistic-Based Airport Pavement Design, COE Report No 4, University of Illinois at Urbana-Champaign, Urbana IL.

[11] EN 14227-10:2006: Hydraulically bound mixtures Specifications - Part 10: Soil treated by cement.

[12] EN 14227-13:2006: Hydraulically bound mixtures Specifications - Part 13: Soil treated by hydraulic road binder.

\section{Contact information:}

Ksenija DJOKOVIĆ, PhD, BSGeoE, principal technical associate

(Corresponding author)

IMS Institute

Bulevar vojvode Mišića 43, 11000 Belgrade, Serbia

ksenija.djokovic@institutims.rs

Simo TOŠoVIć, MsC

Institute for Roads

Kumodraska 257, 11000 Belgrade, Serbia

simo.tosovic@gmail.com

Ksenija JANKOVIĆ, PhD, BSCE, principal research fellow

IMS Institute

Bulevar vojvode Mišića 43, 11000 Belgrade, Serbia

ksenija.jankovic@institutims.rs

Nenad ŠUŠıĆ, PhD, BSCE, principal research fellow

IMS Institute

Bulevar vojvode Mišića 43, 11000 Belgrade, Serbia

nenad.susic@institutims.rs 